\title{
Role of Diet in Pre-Menstrual and Post-Menstrual Women
}

\author{
Harmanjot Kaur**1, Roopjot Kochar ${ }^{2}$ \\ ${ }^{1}$ University School of Hotel Management, Desh Bhagat University, Mandi Gobindgarh \\ ${ }^{2}$ Ayurvedic Physician and Nutritionist, Khanna-141401
}

"Corresponding Author: Harmanjot Kaur, University School of Hotel Management, Desh Bhagat University, Mandi Gobindgarh, E-mail: harmankochar@yahoo.co.in

\begin{abstract}
Menopause is the physiological cessation of menses associated with declining of ovarian functions. It is a normal biological shift in mid to late 30's, when estrogen and progesterone levels decline gradually leading to decline in all reproductive functions. Menopause affects the quality of life of a woman and besides causing commonly reported symptoms including hot flushes, night sweats, sleep disturbances, urinary frequency, vaginal dryness, poor memory, anxiety and depression. The present study has been conducted on 200 females belonging to different cities of Jammu to look in to the association of dietary pattern and their menopausal status. The data was collected from the selected females on selected variables such as menopausal status, dietary habits including number of meals taken per day, skipping meals, frequency of junk foods, sweet preparations eating while watching TV or working on computers, type of oil used and consumption of milk. The selected dietary habits consuming have been observed to be associated with the higher rates of obesity among the selected pre-menopausal and the post-menopausal females.
\end{abstract}

Keywords: Menopause, Dietary Habits, Junk Foods, Obesity

\section{INTRODUCTION}

Menopause is defined as final menstruation. It is the final stoppage of menses in a middle aged woman. Normally with age, the ovaries start to slow the production of hormone like estrogen, progesterone and testosterone. Menopause occurs due to decline in female hormone levels during their late 40's or early 50 's, signaling the end of the fertile phase of a woman's life. Menopause occurs naturally, or it can be caused by surgery, chemotherapy or radiation. The average age of the natural menopause is $47.8 \mathrm{yrs}$ in India and 51.4 yrs in western countries ${ }^{[1]}$. Menopausal age differs from country to country but the average age for menopause is around 5052 years. Menopausal age in Turkey is between 47 and 49 years while in Egypt, it is 48 years, and between 50 and 52 years in Jordan ${ }^{[2]}$. Around menopause there are often hot flashes which typically last 30 seconds to ten minutes and may be associated with shivering, sweating and reddening of the skin. Other symptoms may include vaginal dryness, trouble sleeping migraine, rapid heartbeat, dysfunctional uterine bleeding, joint pain, muscle pain, depression mood, heart diseases and osteoporosis ${ }^{[2]}$. The age at natural menopause depends on various factors like genetic, environmental, socioeconomic, reproductive, dietary, and lifestyle of which some like null parity, vegetarian diet, smoking, high fat intake, cholesterol, and caffeine accelerates. The correlation between diet and menopause has not been extensively studied; however, whatever studies have been done till now point towards role of high intake of total calories, fruits, and proteins in delaying the menopausal, while high polyunsaturated fat intake accelerates it. The role of dietary soy, total fat, saturated fat, red meat, and dietary fiber in determining the menopausal symptoms has been controversial and needs further studies to substantiate it ${ }^{[3]}$.

\section{Materials And Methods}

The present study has been conducted on 200 females belonging to different cities of Jammu to look into the association of dietary pattern and their menopausal status. The information regarding menopausal history of the selected females and their dietary intake pattern including number of meals taken per day, skipping meals, frequency of junk foods, sweet preparations was collected from each subject and recorded on the pre-printed questionnaire.

\section{RESUltS AND DisCUSSION}

Figure 1 depicts that majority (69.00 per cent) of the females selected for the present study were 
vegetarians followed by 29.00 per cent of them who were non vegetarians and the remaining 2.00 per cent were ovo vegetarians. Among the pre-menopausal females majority (70.73 per cent) were vegetarians followed by 27.64 per cent non vegetarians and the remaining 1.63 per cent of the pre-menopausal females were ovo vegetarians. Among the post-menopausal females majority (63.64 per cent) were found to be vegetarians followed by 33.76 per cent who were non vegetarians and the remaining 2.60 per cent of them were ovo vegetarians.

It is observed from the Figure 2 that majority (68.00 per cent) of the females were pure vegetarian followed by 16.50 per cent of the females who had taken non vegetarian or ovo vegetarian diet occasionally. (10.00 per cent) of the females had taken non vegetarian or ovo vegetarian diet weekly while 4.00 per cent of them had taken it twice a week and remaining 1.50 per cent of the females were having non vegetarian or ovo vegetarian diet daily. Among the pre-menopausal females, majority (70.73 per cent) were pure vegetarians followed by 12.20 per cent who had taken non vegetarian diet weekly. 11.38 per cent of them had taken it occasionally while 4.06 per cent had taken it twice a week and remaining 1.63 per cent of them had taken the non-vegetarian or ovo vegetarian diet daily. Among the postmenopausal females, majority (63.64 per cent) were pure vegetarians followed by (24.68) per cent who had taken non vegetarian foods occasionally. 6.49 per cent of them had taken it weekly while 3.90 per cent were taking it twice a week and remaining 1.29 per cent of them had taken the non-vegetarian or ovo vegetarian diet daily. The pre-menopausal and post-menopausal females were in majority who were taking vegetarian diet. However, it was reported that the higher intake of non-vegetarian diet was associated with the late menopause [4].

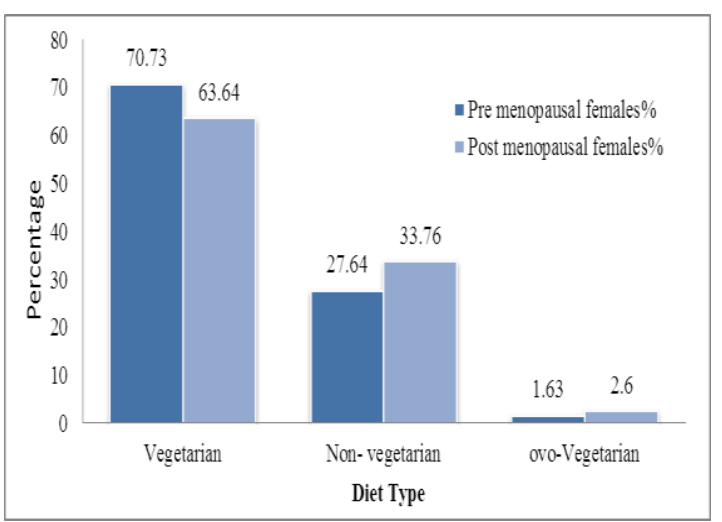

Figure1. Distribution of Subjects on the Basis of Diet Type

ARC Journal of Nutrition and Growth

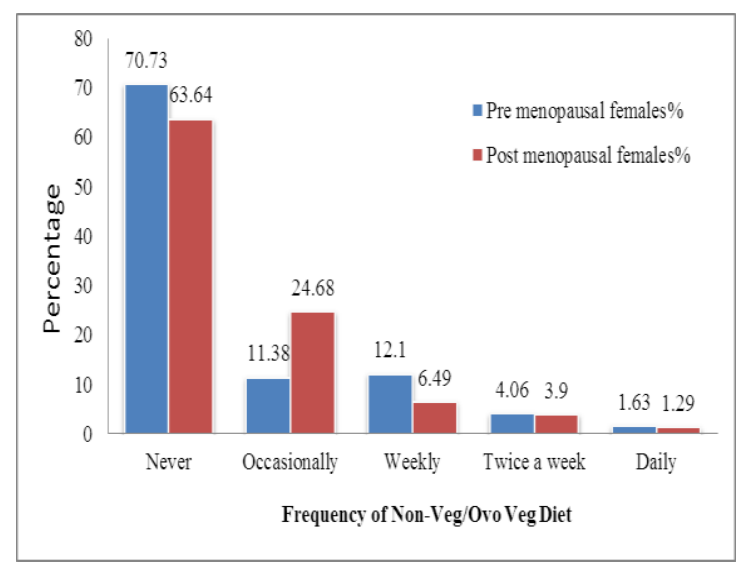

Figure2. Distribution of Subjects on the Basis of Frequency of Non-Vegetarian/Ovo Vegetarian Diet

Figure 3 depicts that majority ( 61.00 per cent) of the females had taken 3 meals per day followed by 36.00 per cent of the females who were habitual of taking 2 meals per day and remaining 3.00 per cent of them were taking 4 meals per day. Among the pre-menopausal females, majority (69.11 per cent) who were the habitual of taking 3 meals a day followed by 27.64 per cent of them who were taking only 2 meals per day and the remaining 3.25 per cent of them were taking 4 meals per day. Among the post-menopausal females, majority (49.35 per cent) had taken 2 meals followed by 48.05 per cent who were taking 3 meals per day and the remaining 2.69 per cent of them were taking 4 meals per day. It is shown from the present study results that majority of the females $(61.00$ per cent) were habitual of taking 3 meals per day. However, it was observed that a significant decrease in BMI was correlated with the number of meals taken among menopausal females ${ }^{[5]}$.

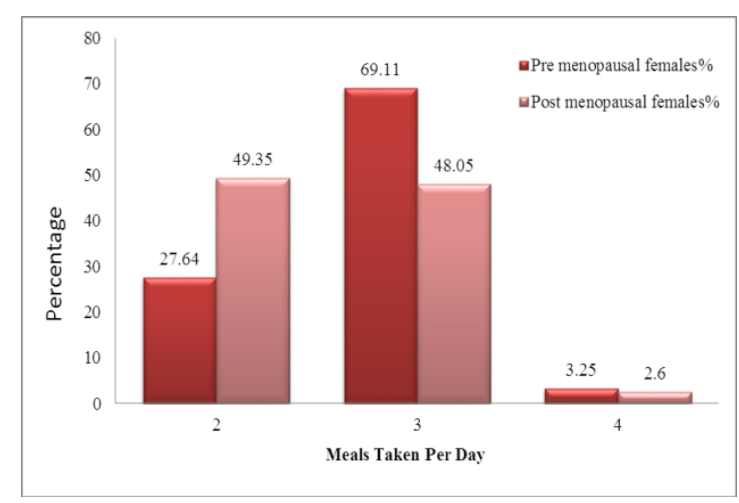

Figure3. Distribution of subjects according to the number of meals taken per day

It is revealed from figure 4 that the majority (62.00 per cent) of the females selected for the present study were not habitual of skipping any meal followed by 22.50 per cent of them who were skipping lunch and 15.50 per cent of them were habitual of skipping their breakfast meal. However, none of the females were found to Page |11 
skip dinner meal. Among the pre-menopausal females, majority (70.73 per cent) were not skipping any meal followed by 16.26 per cent who used to skip lunch and 13.01 per cent of them were into habit of skipping breakfast. Among the post-menopausal females, also, majority (48.05 per cent) were not skipping any meal followed by 32.47 per cent who were skipping their lunch and 19.48 per cent of postmenopausal females were skipping breakfast meal. However, it was reported that meal skipping was negatively impacts on the health and also associated with the greater obesity rates among females ${ }^{[6]}$.

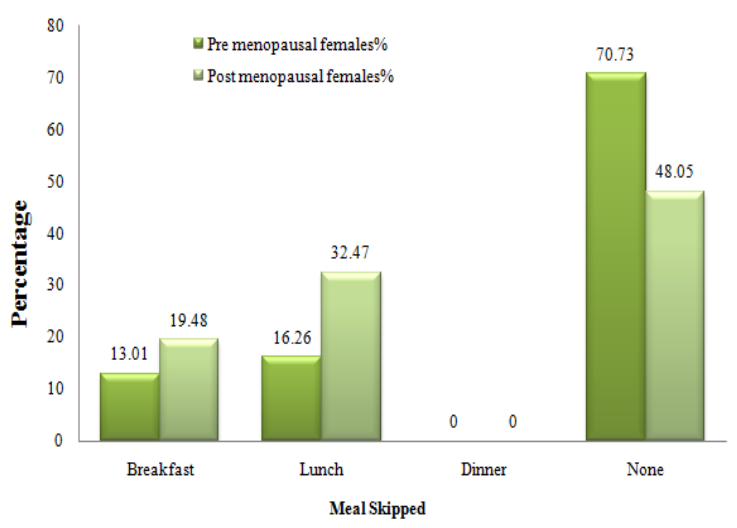

Figure4. Distribution of Subjects on the Basis of Meal Skipped.

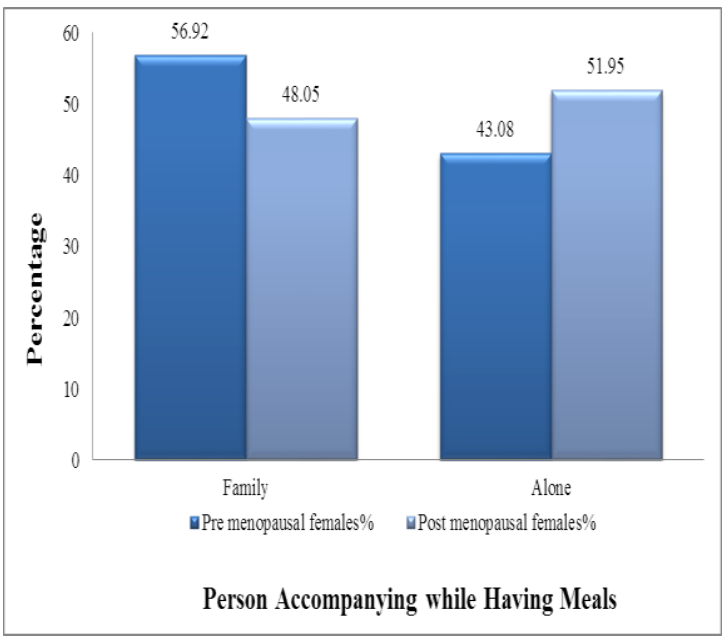

Figure 5: Distribution of subjects according to the person accompanying while having meals.

Figure 5 shows that majority, (53.50 per cent) of the females had a habit of having meals with the family while 46.50 per cent of the females who were habitual of having meals alone. Among the pre-menopausal females, majority (56.92 per cent) had a habit of having meals with family and 43.08 per cent of them were habitual of having meals alone. However, amongst the postmenopausal females, majority (51.95 per cent) had a habit of having meals alone while (48.05 per cent) of them who were having meals with family. Thus, it is shown from the present study results that majority of the pre - menopausal females were found to be habitual of having meals with their families and majority of the post -menopausal females were habitual of having their meals alone.

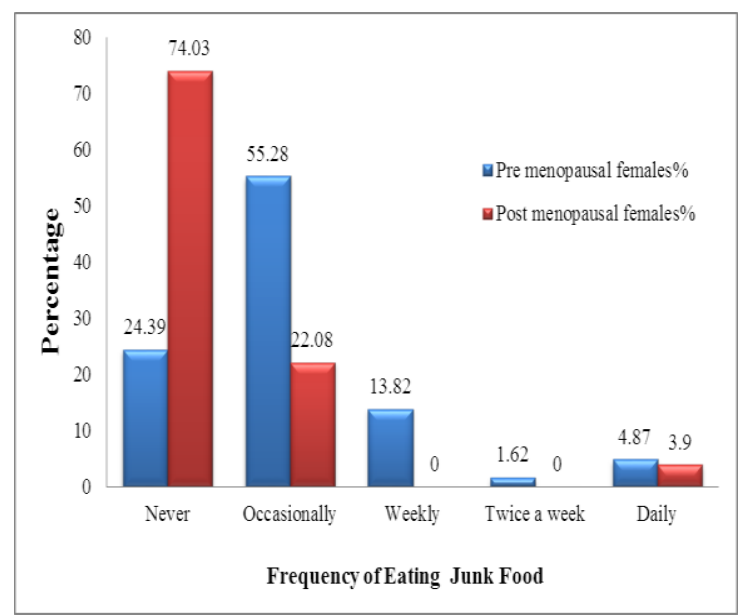

Figure6. Distribution of Subjects according to Frequency of Eating Junk Food.

It is observed from figure 6 that majority ( 43.50 per cent) of the females were not taking any kind of junk foods like noodles, burgers, chips etc. followed by 42.50 per cent of the females who were taking junk food occasionally. 8.50 per cent of females were taking it weekly while 4.50 per cent of them were fond of having junk foods daily. Remaining (1.00) per cent of females were habitual of taking junk food twice a week. Among the pre-menopausal females, majority (55.28 per cent) were taking junk food occasionally followed by 24.39 per cent of them who were not habitual of taking any junk foods at present while 13.82 per cent of them were habitual of consuming junk foods weekly and (4.87) per cent were taking junk foods daily and the remaining (1.62 per cent) were habitual of taking junk foods twice a week. However, among the post-menopausal females, majority (74.03 per cent) were not habitual of taking any junk foods followed by 22.08 per cent who were taking junk foods occasionally. (3.90 per cent) of them had been consuming one or the type of junk foods daily. It is shown from the present study results that majority of the premenopausal and post-menopausal females reported that they were not habitual of taking any junk food. It was also observed that there was no strong relationship observed for fast food intake and weight gain in post-menopausal females ${ }^{[6]}$. However it was reported that consumption of fried foods and junk foods were 
associated with increasing weight gain in females ${ }^{[7]}$.

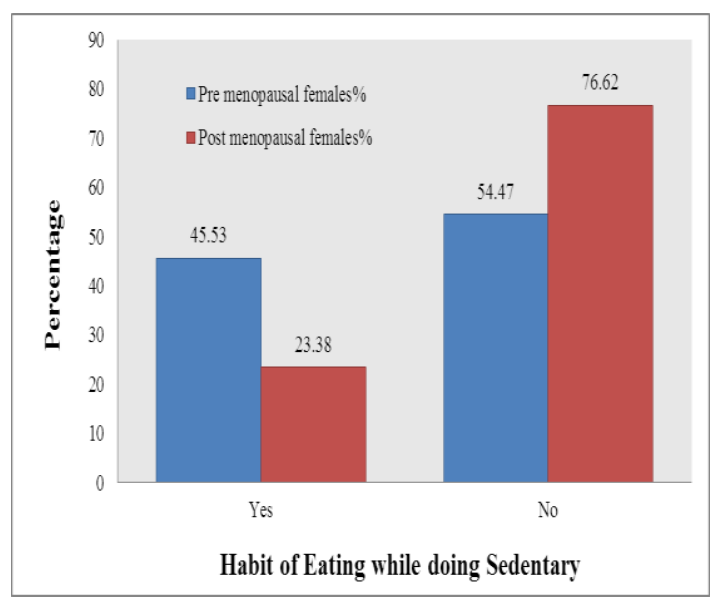

Figure7. Distribution of Subjects According to their Habit of Eating While Doing Sedentary Tasks.

Figure 7 shows that majority, (63.00 per cent) of the females selected for the present study do not have a habit of eating while doing sedentary tasks like watching TV or using computer while 37.00 per cent of the females were habitual of eating while doing sedentary tasks. Among the pre-menopausal females, (54.47 per cent) do not have a habit of eating while doing sedentary tasks and 45.53 per cent of them were in habit of eating while doing sedentary tasks. Among the post-menopausal females, majority (76.62 per cent) does not have a habit of eating while doing sedentary tasks and (23.38) per cent of them were habitual of eating while doing sedentary tasks. Thus, it is shown from the present study results that majority of the pre-menopausal and post-menopausal females were not habitual of eating while doing sedentary tasks like watching $\mathrm{TV}$ or working on computer.

Figure 8 depicts that majority (56.75 per cent) of the females selected for the present study were habitual of eating meals while doing sedentary tasks like watching TV or using computer followed by 20.27 per cent of females who were taking tea. (13.51) per cent of the females were habitual of taking snacks and 8.10 per cent of them had taken fruits and the remaining (1.35 per cent) of them were taking junk foods while doing sedentary tasks. However, among the premenopausal females majority (58.93 per cent) were habitual of eating meals while doing the sedentary tasks like watching TV or using computer followed by 16.07 per cent were taking tea only while 14.29 per cent of the premenopausal females were habitual of taking snacks and 8.93 per cent of them were taking fruits only. The remaining (1.78 per cent) of them were in habit of taking junk foods. Among the post-menopausal females majority $(50.00$ per cent) were habitual of eating meals while doing sedentary tasks like watching TV or using computer followed by 33.33 per cent of them who were taking tea while 11.11 per cent of them were taking snacks and the remaining 5.56 per cent of them were in habit of taking fruits . It is thus, revealed from the present study that there is significant difference among pre-menopausal and post-menopausal females in the habit of eating while watching TV or working with computer, which may be a causative factor for higher prevalence of obesity among the pre-menopausal females.

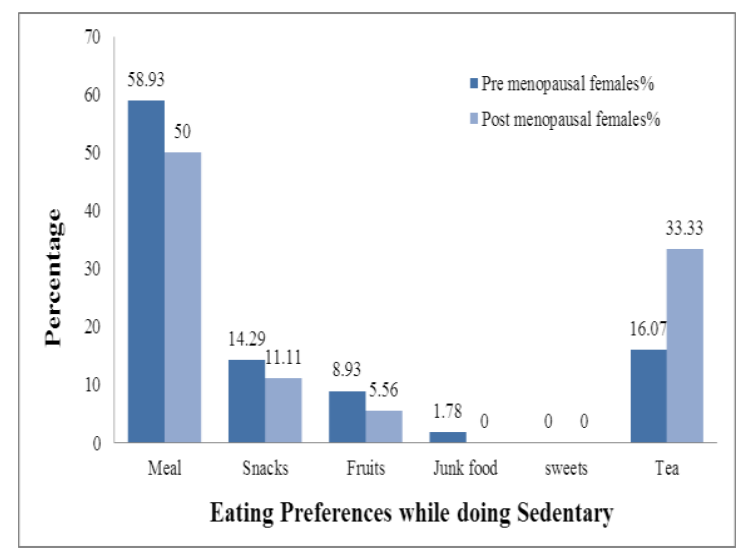

Figure8. Distribution of Subjects According to their Eating Preferences While Doing Sedentary Tasks.

Figure 9 reveals that majority, (53.00 per cent) of the females were habitual of taking fruits occasionally followed by 32.00 per cent of females who were taking fruits daily. 10.00 per cent of them were taking it weekly and the remaining (5.00 per cent) of females were taking fruits twice a week. Among the premenopausal females, majority (41.46 per cent) were taking fruits occasionally followed by (40.65) per cent of them who were habitual of taking fruits daily. 12.20 per cent were taking fruits weekly while (5.69) per cent of them were taking fruits twice a week. However, among the post-menopausal females, majority (71.43 per cent) were taken fruits occasionally followed by 18.18 per cent of them who were taking fruits daily. (6.49 per cent) were taking fruits weekly while 3.90 per cent of them were taking fruits twice a week. It is thus, observed from the present study that majority of the premenopausal and post-menopausal females were habitual of taking fruits occasionally. It was reported that high consumption of fruits delay the onset of menopause in females ${ }^{[3]}$.

Page $\mid 13$ 


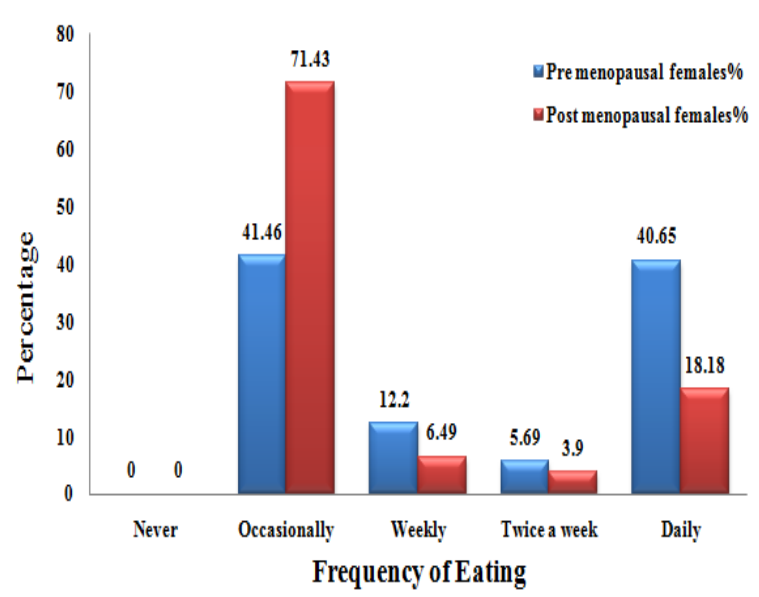

Figure9. Distribution of subjects on the basis of frequency of eating fruits.

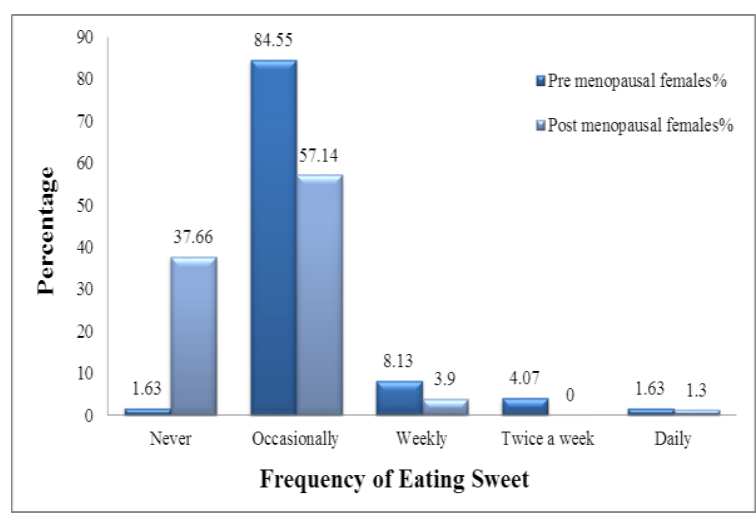

Figure10. Distribution of subjects according to Frequency of Eating Sweet Preparations.

Figure 10 shows that the majority $(74.00$ per cent) of the females was habitual of taking sweet preparations such as sweets, cakes, pastries etc. occasionally followed by 15.50 per cent of them who had never taking sweets, cakes, pastries etc. 6.50 per cent of females were taking sweets weekly and 2.50 per cent of them were taking sweet preparations twice a week. Remaining 1.50 per cent of them were in habit of taking the same. Among the premenopausal females, majority ( 84.55 per cent) were found to be habitual of taking sweet preparations occasionally followed by 8.13 per cent who were taking it weekly. 4.07 per cent of the pre-menopausal females were taking it twice a week while 1.63 per cent of them were in habit of taking sweets twice a week and another 1.63 per cent of females had never taken sweets, cakes, pastries etc. Among the post-menopausal females, majority ( 57.14 per cent) were habitual of taking sweets, cakes, pastries etc. Occasionally followed by 37.66 per cent who had never taken sweets, cakes, pastries etc. 3.90 per cent of them were taking weekly and the remaining 1.30 per cent of post-menopausal females was in habit of taking sweets, cakes, pastries etc. daily. It was suggested that there was a significant positive correlation between higher BMI and weekly amounts of consumption of sweets in menopausal females. However, only 3.90 per cent of the postmenopausal females of the present study have been found taking sweets weekly [8].

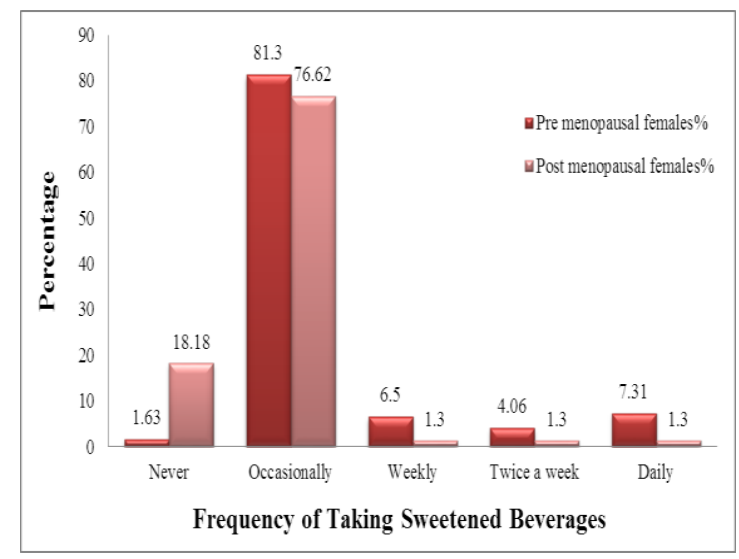

Figure11. Distribution of subjects according to Frequency of Taking Sweetened Beverages.

Figure 11 reveals that majority (79.50 per cent) of the females were habitual of taking sweetened beverages (like sharbat, sweet lassi, soft drinks etc) occasionally followed by 8.00 per cent of females who were found to be habitual of never taking the sweetened beverages. (5.00 per cent) of females were taking it daily and 4.50 per cent of them were taking the sweetened beverages weekly while the remaining 3.00 per cent of them were in habit of taking sweetened beverages twice a week. Among the pre-menopausal females, majority ( 81.30 per cent) were habitual of taking sweetened beverages (like sharbat, sweet lassi, soft drinks etc) occasionally followed by 7.31 per cent who were taking it daily. 6.50 per cent were taking sweetened beverages weekly and 4.06 per cent of them were in habit of taking sweetened beverages twice a week. Remaining 1.63 per cent of them had never taken the sweetened beverages. However among the postmenopausal females, majority (76.62 per cent) were habitual of taking sweetened beverages occasionally followed by 18.18 per cent who were not taking sweetened beverages. 1.30 per cent who were taking sweetened beverages weekly while another 1.30 per cent of them were taking twice a week. The remaining 1.30 per cent of them was habitual of taking the sweetened beverages daily. It is thus revealed from the present study results that majority of the pre-menopausal and post-menopausal females of the present study were habitual of taking sweetened beverages occasionally. 
However, it was reported that higher intake of sweetened beverages like soft drinks and fruit juice were significantly associated with higher BMI in menopausal females ${ }^{[5,9]}$.

Figure 12 depicts that majority (58.50 per cent) of the females were consuming mustard oil followed by 36.50 per cent of females who were consuming refined oil. 4.00 per cent of them were habitual of consuming dalda and the remaining 1.00 per cent of them were habitual of consuming desi ghee. Among the premenopausal females majority (49.59 per cent) were habitual of consuming refined oil followed by 44.72 per cent who were consuming mustard oil. (4.07) per cent of them were consuming dalda and the remaining 1.62 per cent of them were habitual of consuming desi ghee. Among the post-menopausal females majority (80.52 per cent) were in habit of consuming mustard oil followed by 15.58 per cent who were consuming refined oil. 3.90 per cent of them were consuming dalda. It is revealed from the present study results that the majority of the premenopausal and post-menopausal females were consuming unsaturated oil (Mustard oil and refined oil) as a medium of cooking for their diets. However, it was suggested that higher intake of unsaturated oil/fats like mustard oil and refined accelerates natural menopause while intake of saturated fats like Dalda and butter has no effect on menopause[8].

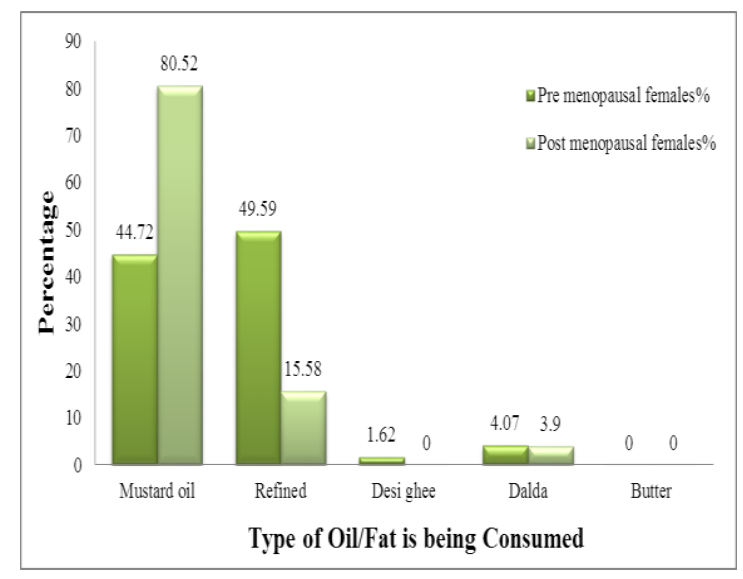

Figure12. Distribution of subjects according to the type of oil/fat is being consumed.

It is observed from Figure 13 that majority (61.50 per cent) of the females were habitual of consuming toned milk followed by 30.00 per cent of them who were habitual of consuming full cream milk and the remaining 8.50 per cent of them were consuming double toned milk. However, among the pre-menopausal females majority (69.10 per cent) were habitual of consuming toned milk followed by 26.83 per cent of them who were consuming full cream milk and the remaining 4.07 per cent of them were in habit of consuming double toned milk. Among the post-menopausal females majority (49.36 per cent) were habitual of consuming toned milk followed by 35.06 per cent of them who were consuming full cream milk and remaining 15.58 per cent of them were consuming double toned milk. Thus, it is shown from the present study results that majority (61.50 per cent) of the pre-menopausal and postmenopausal females were habitual of consuming toned milk.

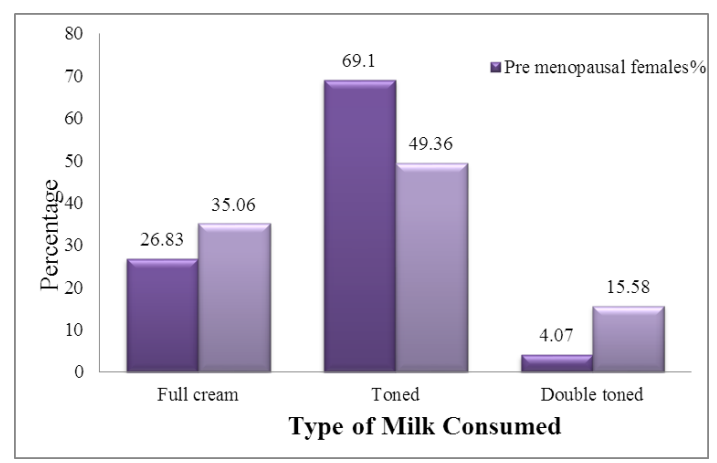

Figure13. Distribution of subjects according to the type of milk consumed

Figure 14 depicts that the majority (30.00 per cent) of the females selected for the present study were habitual of taking milk daily followed by 27.00 per cent who were taking milk twice a week. (19.00) per cent of females were in habit of taking milk weekly while 18.50 per cent of them who were used to taking milk once a week and the remaining 5.50 per cent of them were not habitual of taking milk. Among the pre-menopausal females majority ( 34.15 per cent) were habitual of taking milk daily followed by 31.71 per cent who were taking milk twice a week. 17.07 per cent were taking milk once in a week while 13.82 per cent were taking it weekly and the remaining 3.25 per cent of them who were not habitual of taking milk. Among the post- menopausal females majority (27.27 per cent) were habitual of taking milk weekly followed by 23.38 per cent who were taking milk daily. (20.78 per cent) were taking milk once in a week while 19.48 per cent were in habit of taking milk twice a week and the remaining 9.09 per cent of them were not habitual of taking milk. It is thus, revealed from the present study results that majority of the premenopausal and post-menopausal females selected for the study were habitual of consuming toned milk daily. In pre-menopausal 
females, milk consumption was associated with the timing of menopause, as the milk contains hormones and growth factors that could potentially affect the menopausal timing among pre-menopausal females ${ }^{[10]}$.

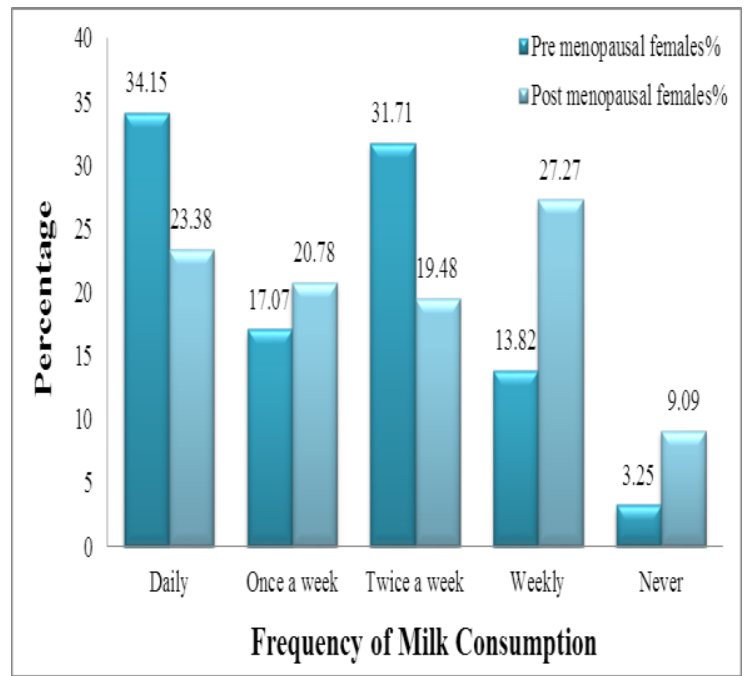

Figure14. Distribution of subjects on the basis of their Frequency of Milk Consumption.

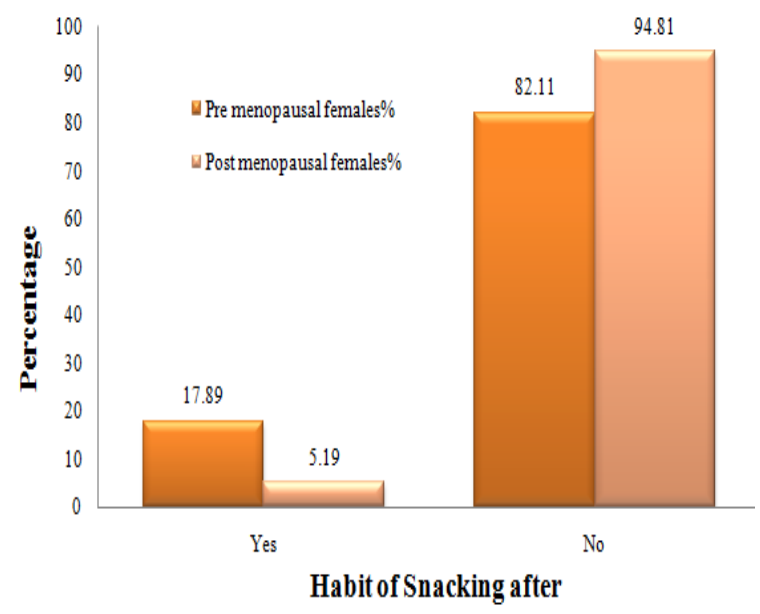

Figure15. Distribution of subjects according to the habit of Snacking after Dinner.

Figure 15 shows that majority ( 87.00 per cent) of the females were not habitual of taking snacks after dinner while 13.00 per cent of females were habitual of snacking after dinner. Among the pre-menopausal females, majority (82.11 per cent) were not habitual of snacking after dinner while 17.89 per cent of them who were habitual of snacking after dinner. Among the post-menopausal females, majority (94.81 per cent) were not habitual of snacking after dinner while 5.19 per cent of them were habitual of snacking after dinner. It is thus, observed from the present study results that majority of the pre-menopausal and post-menopausal females were not habitual of snacking after dinner.

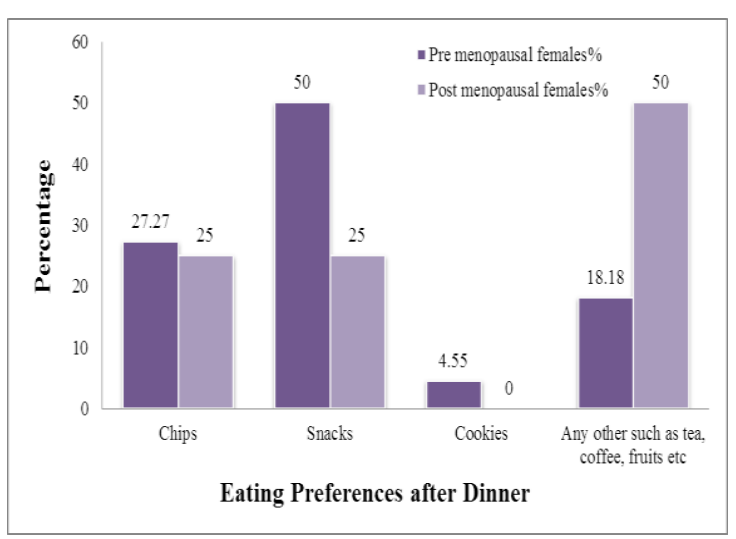

Figure 16. Distribution of subjects according to the Eating Preferences after Dinner.

It is depicted from figure 16 that majority (46.15 per cent) of the females selected for the present study were habitual of taking snacks after dinner followed by 26.92 per cent of females who were taking chips. (23.08 per cent) of females were habitual of taking tea and fruits and the remaining 3.85 per cent of them were taking cookies after dinner. Among the premenopausal females majority (50.00 per cent) were habitual of taking snacks after dinner followed by 27.27 per cent who were taking chips. (18.18 per cent) of them were in habit of taking tea and fruits and the remaining 4.55 per cent of them were taking cookies after dinner. However, among the post-menopausal females majority (50.00 per cent) were habitual of taking tea and fruits after dinner followed by 25.00 per cent who were taking chips and the remaining 25.00 per cent of them were in habit of taking snacks after dinner. Thus, it is shown from the present study results that majority of the premenopausal and post-menopausal females were habitual of taking snacks after dinner.

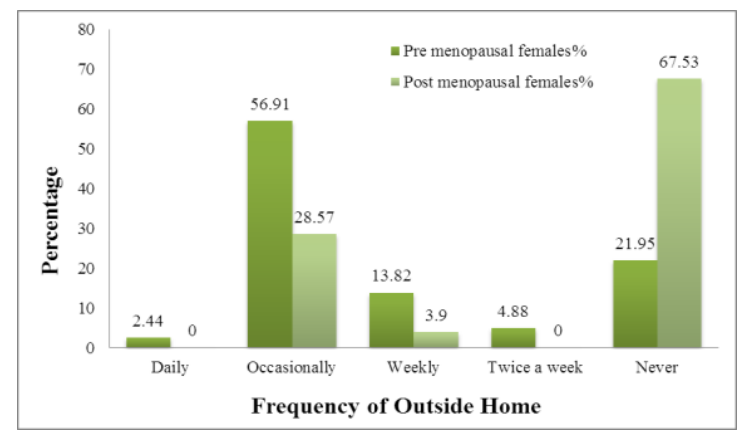

Figure17. Distribution of Subjects According to the Frequency of Outside Home Eating.

It is revealed from Figure 17 that majority (46.00 per cent) of the females were in habit of occasionally going for outside home eating followed by 39.50 per cent of the them who were not habitual of going for outside home eating. (10.00 per cent) of them were weekly 
going for outside home eating while 3.00 per cent of them were going twice in a week and the remaining 1.50 per cent of them were habitual of daily outside home for eating. Among the pre-menopausal females majority (56.91 per cent) were occasionally going for outside home eating followed by 21.95 per cent who were not habitual of going for outside home eating. 13.82 per cent of them were going for outside home eating weekly while 4.88 per cent of them were going twice in a week and the remaining 2.44 per cent of the pre-menopausal females selected for the present study were habitual of daily going for outside home eating. Among the postmenopausal females majority (67.53 per cent) were not habitual of outside home eating followed by 28.57 per cent who were occasionally going for outside home eating and the remaining 3.90 per cent of them were weekly going for outside home for eating. Thus, it is observed from the present study results that majority of the females were going for outside home eating occasionally only. It was suggested that there is a significant relationship between outside home eating and gaining weight among overweight /obese post-menopausal females. However findings of other investigators also reported that restaurant eating plays an important role in obesity development among females [7].

\section{Conclusions}

Vegetarian diets have been observed among majority of the pre-menopausal and postmenopausal females and among those who were taking non vegetarian diet, they were taking it occasionally. They also had a habit of taking meals with their families. The pattern of taking 3 meals per day is shown in majority of both pre-menopausal and post-menopausal females and among those who were skipping meals, they were in habit of skipping their lunch meal only. The pre-menopausal and post-menopausal females in majority were not habitual of eating while doing sedentary tasks like watching TV or working on computer. Among those who had a habit of eating, they were taking meals at the time of watching TV or using computer and were not habitual of eating any snacks or junk foods. The majority of the pre-menopausal and post-menopausal females were habitual of taking sweet preparations, sweetened beverages, fruits, going for outside home eating occasionally while they were not habitual of taking any junk foods. The pre-menopausal and post-menopausal females in majority were found to be habitual of consuming unsaturated oil such as mustard oil and vegetables oil as a medium of cooking for their diet. Both the premenopausal and post-menopausal females in majority were found to be habitual of taking toned milk daily. The majority of the premenopausal and post-menopausal females were not habitual of nibbling after dinner. Among those who were in habit of nibbling, they were taking snacks only. Thus, dietary habits such as number of meals taken per day, skipping meals, frequency of junk foods, sweet preparations, eating while watching TV or working on computers, type of oil and milk consuming have also been observed to be associated with the higher rates of obesity among the selected premenopausal and the post- menopausal females.

\section{REFERENCES}

[1] Kaur H, Kochar R. Obesity and Menopause: A New Nutritional Concern. ARC Journal of Nutrition and Growth. 2015; 1(1): 8-13.

[2] Güner SG, Gençosman H, et al. Women's health promotion behavior as related to osteoporosis in the period of menopause. International Journal of Science \& Healthcare Research. 2017; 2(2): 46-55.

[3] Sapre S and Thakur R. Lifestyle and dietary factors determine age at natural menopause. Journal of Mid-Life Health. 2014; 5(1):3-5.

[4] Negal G, Altenburg HP, NietersA et al. Reproductive and dietary determinants of the age at menopause in EPIC- Heidelberg. Maturitas. 2005; 52:337-47

[5] Samir T, Midhat J and Azijada B. Nutritional status and dietary habits of menopausal women. Food in health and diseases, scientific professional J Nutr Diets. 2014; 3(2):116-125

[6] Angela K, Shirley AA, Beresford, et al. Selfmonitoring and eating related behaviors associated with 12 month weight loss in post menopausal overweight to obese women. J AcadNutr Diet. 2011; 112(9):1428-1435

[7] Barone GB, Kinzel LS, Chang YF et al. Short and long term eating habit modifications predicts weight change in overweight postmenopausal women: results from the women study. Acad J Nutr Diet. 2012; 112(9):13471355.

[8] Gold EB. The timing of the age at which natural menopause occurs. ObstetGynecolClin NorthAm. 2011; 38(3):425-440 
[9] Singh M. Early age of natural menopause in India, a biological marker for early preventive health programs. Climacteric. 2012; 15:581-6.
[10] Carwile JL, Willett WC and Michels KB. Consumption of low fat dairy products may delay natural menopause. J Nutr. 2013; 143(10):1642-50.

Citation: Harmanjot Kaur, Roopjot Kochar Role of Diet in Pre-Menstrual and Post-Menstrual Women. ARC Journal of Nutrition and Growth. 2017; 3(2):10-18. doi: dx.doi.org/10.20431/2455-2550.0301003.

Copyright: (C) 2017 Authors. This is an open-access article distributed under the terms of the Creative Commons Attribution License, which permits unrestricted use, distribution, and reproduction in any medium, provided the original author and source are credited. 